\title{
Impact of Inoculums of Dry Batch Type Digesters on Resultant Compost Quality
}

\author{
K.A.R.K. Kodituwakku, M.D.M.D.W.M.M.K. Yatawara* \\ Department of Zoology and Environmental Management, University of Kelaniya, Sri Lanka \\ *mmkyat@kln.ac.lk
}

\begin{abstract}
Anaerobic digestion (AD) of municipal solid waste is significant in terms of energy and material recovery. The resultant sludge from $\mathrm{AD}$ is $100 \%$ organic and used as a fertiliser. The batch type biogas digesters established by National Engineering Research and Development Center in Dikowita in Wattala is one of the waste to energy projects established in the Western Province in Sri Lanka. Pre-sorted market and green waste in the area are used as the substrate while three cow dung layers (as top, middle and bottom) are applied as inoculums in the digesters. However, continuous supply of cow dung to the plant has become a challenge at present. Hence, the top cow dung layer is replaced by one month old previously generated sludge by the plant. After generating biogas, sludge is composted by means of windrow composting and sent to the market. The aim of the present study was to assess the quality of resultant compost due to the replacement of top inoculum layer by previously generated sludge. Nine laboratory digester tanks were set up and filled representing three treatments (with three replicates), in which Treatment-1, Treatment-2 and control had cow dung, previously generated sludge and organic waste respectively as top inoculum layer. After completion of AD process, resultant organic sludge samples were air dried. The resultant compost samples from digesters were sieved through $4.75 \mathrm{~mm}$ aperture (mesh no.4). Physical, chemical and biological parameters of resultant compost were analysed. The results were subjected to One-Way ANOVA followed by Tukey's test to see whether there were significant differences among three treatments and compared with Sri Lanka Standard 1246:2003. The results revealed that, the potassium contents $\left(\mathrm{K}_{2} \mathrm{O} \%\right)$ in the samples were insufficient $(<1.0 \%)$. The moisture of Treatment-1, Treatment-2 and Control were $44.42 \%$, $47.34 \%$ and $51.83 \%$ respectively and significantly different from each other $(\mathrm{p} \leq 0.05$; ANOVA). However, the colour, odour, particle size, sand content, $\mathrm{pH}$, organic carbon, total nitrogen, phosphorous, $\mathrm{C} / \mathrm{N}$ ratio and viable weed seeds were comparable to Sri Lanka Standard 1246:2003, suggesting that the resultant compost could be used as a soil amendment.
\end{abstract}

Keywords: Biogas, Compost, Digestion, Waste, Cow dung layer 